\title{
English Language Teaching (ELT) in Iranian Universities in Brief
}

\author{
Hossein Jamshidi Avanaki \\ Payame Noor University, Qazvin Branch, Qazvin, Iran \\ Bahador Sadeghi \\ Islamic Azad University, Takestan Branch, Takestan, Iran
}

\begin{abstract}
In this article ELT in Iranian universities will be briefly introduced with its problems which are related mainly to lack of the most university instructors training, class settings; textbooks and more than all applied teaching approaches that usually operate theoretically rather than practically. To know a language means to use it efficiently. Since English is not used as a second language in Iranian Society, therefore, it should be taught/learnt for its application and we see this problem adequately in Iranian Language instructional system. This problematic issue can be reduced or removed from the system through a fit and suitable practiced way of teaching. Having identified and argued the problems, the authors forward some useful and applicable recommendations and finally the conclusions will end the article.
\end{abstract}

Index Terms - English language teaching, Iranian Universities

\section{INTRODUCTION}

Qualitative Method Planning and Procedure Implementation is one of the most important issues in university education. Therefore it is, vital to continue working on its qualitative enhancement which is the practical step. That results a better teaching method to the benefit of a higher education system for students.

It is suggested that Iranian classes can gain higher and better achievements. To achieve this, students are invited by the teacher to discuss on anecdotes that are motivating and are beneficial to the learners.

In principle, explorative questions are the main points in the syllabus of each session, which would be extracted from their available textbook materials.

Smith (2006) asserted; "One of the attributes of a profession is a body of knowledge which is not only current, but which has roots in the past." Having familiarization with the methodology of ELT professionally can change the learning level of the learners. He also reviewed Wren's noble work on the issue. Wren offered the teaching English for practical purposes and as a basis for further study. He has offered some principles for teaching which included;

a. "Teach through the senses;

b. Let the pupil learn by doing;

c. Start from what the pupil knows and go on to what he does not know;

d. Teach inductively;

e. Encourage self-teaching;

f. Use of present continuous."

Kondo and Ying-Ling (2004) designed a study to develop strategies that students use to cope with their difficulties in English classrooms. They recommended some strategies as follows:

"Preparation \{e.g. studying hard, trying to obtain good summaries of lecture notes\}, Relaxation \{e.g. taking a deep breath, trying to calm down\}, Positive Thinking \{e.g. imagining oneself giving a great performance, trying to enjoy the tension\}, Peer Seeking \{e.g. looking for others who are having difficulty controlling their anxiety, asking other students if they understand the class p.80.\}

Sayer (2005) in identifying and organizing elements of interaction noted that;

"Rather than prescribe what the course include, I wanted the content to reflect what the students actually needed practice with. In order to isolate which aspects I would treat directly, I set an initial task, various tasks of the same basic type were used during the two weeks, and another at the end, so that the students could self-evaluate their progresses."

There is no question that a well trained teacher can teach more effectively, both theoretically and practically, than the one who has not been under any kind of training. That is why initial teacher training is designed ultimately to improve classroom learning and practice. The reason is that the theory provides the prospective teachers with knowledge and content and a broad insight into teaching, whereas practice helps these teachers exercise handling a class by selecting suitable teaching strategies and methods. English language teaching in Iran, since its origins, has not been appropriately designed, focused and targeted to meet the real and practical needs of its learners. For example, in the Iranian university setting, the main concern at the present is for reading rather than English application. Oral performance activities are neither included in English course books, nor offered by the teachers of English. As a result, students have little 
opportunity to practise and use the language in classes. These students have a fairly strong background in grammar and vocabulary, but are not able to communicate in English and express their ideas.

All Iranian university students have to take a definite number of English courses (obligatory courses). While the teaching of English language to learners has been carried out for a long time, it is only in the last two decades that professional attention has focused on the target language itself. English learners are non-English speakers and require sufficient mastery of English to meet their target language needs and purposes. Issues such as the lack of teaching approach opportunity and the need to use English in real life situations is clearly an urgent issue as is acknowledged by writers such as Biria \& Tahririan (1994).

Dramatic changes in the various aspects of Iranian society, such as political, cultural, and particularly educational, and advances in technology in the recent years demand new strategies for English teaching/learning process in particular at university level. At this level English should be seen as a "world language" to connect Iran to the world at large. The strategies that are important are those which make the teaching/learning atmosphere creative and provide a critical framework for re-thinking educational objectives.

Therefore, the aims of this article is first to introduce the identified problems of ELT in Iranian universities and propose some teaching strategies which is hoped to be applicable and effective in Iranian university teaching.

\section{PROBLEM}

The most important problem is, in fact, the teachers themselves. Because of a lack of training most of them teach not in English, but in Farsi, most of the time. One of the other reasons is the Iranian students themselves, who often prefer to be quiet and passive in class. This problem is basically related to the Iranian culture and social context which are different from the Western in many respects (Jamshidi Avanaki (1998)). So far, in all classroom interactions it is the teacher who decides what to do or what kind of activities should be performed in class and in the majority of classes the teacher is the sole speaker most of the time and also has the right to speak. As a result, students have no opportunity to practise, at the very least, what has been taught in class or to participate in speaking activities as is supported by Biria and Tahririan (1994).

Iranian university teachers have two main problems with the English textbooks: firstly, most of them find the content difficult since it is often taken from foreign books; secondly, there is no particular approach suitable for teaching the English language content. Iranian university textbooks for English courses are prepared in two periods in which different groups of writers unanimously have provided a variety of English textbooks. In the first, authors such as Bates (1978) produced a set of materials called 'The Nucleus Series'. The second period was after the Cultural Revolution in Iran in 1979-1982. In this period, a variety of textbooks were prepared for different subjects such as physics, chemistry, mathematics, biology and medicine. These textbooks are provided at two levels. At level one, the books contain a collection of relevant materials. For example, one lesson is about general principles of physics while a second is about general principles of chemistry. The level one book is for all basic science students (of physics, chemistry, maths, and biology). Level two is specific to each separate discipline and contains only that subject, such as physics or chemistry. Each lesson in these textbooks has a text as the main body of the lesson, which precedes different kinds of exercises such as comprehension questions, blank-filling exercises and short essay writing questions, but there are no communication exercises in these textbooks. The main difficulties with these textbooks are as follows:

1. English language students begin their English classes with a previously learned linguistic background known to the English teacher. Many teachers and almost all students are not fluent in English, and most of the science and technology lectures are given in Persian, containing potted information often translated from foreign textbooks or directly taken from those sources, referred as "Scaffolding" by Larsen-Freeman \& Long (1991). Whereas, Flowerdew (1994) has gone further and argued that: the need for further research into second language lectures before meaningful statements can be made about lectures which will have concrete effects on pedagogy.

2. Different classes through the medium of English may use different textbooks because they are in different disciplines.

3. The traditional method of learning no doubt affected the attitudes of students towards English: they were predisposed to view it as a content subject rather than as a means of communicating and of acquiring knowledge. Students have avoided using even that small amount of language they have learned. As a result the approaches used are not communicative at all and are not planned on the basis of the English learners' needs.

4. Even students with a strong background in English cannot use the language, because of approaches in which the students do not use the target language and do not practise it.

5. English classes, like other subject classes, are conducted as if they were teacher-centred types of teaching and in fact are not suitable for learner-centred activities, so that some alterations are needed in the approach to teaching.

However, no new method was developed for the new courses; this caused English teaching to become problematic in Iranian universities, particularly in the area of oral skills. These are certain characteristics of English teaching in Iranian universities, as I have observed from my own observations. These are what I found through my research during $1994-$ 1998 as well as experiences I already had from Iranian system.

I have been concerned with the problem of English use by the university students ever since I started my teaching at the university. In most cases the students could not even express themselves which is a key indicator of ELT failures in 
Iranian universities. This led me to search for a solution to solve the problem as to what teaching/learning factors such settings, textbooks and in particular what strategies are effective and how they could be used to improve oral discourse, especially the fluency of the Iranian university students. More precisely, this is important because it will fill the gap of the oral weaknesses of the students through the opportunities which the proposed approach offers to the students. Therefore, I shall introduce some English language teaching methods in Iran which would help provide an English speaking environment through the suitable teaching strategies being introduced and applicable to the Iranian university settings.

The first point to note is that there is no standard and up-to-date teaching approach used in existing English language teaching practised by the teachers at university level. Almost all English classes are still teacher-centred in Iranian universities. Another major difficulty of English language teaching in Iranian universities is that students who can use the most complex scientific discourse in their native language often find themselves in the situation where they cannot comprehend the academic lectures given in English or interact with others in the English language. This is true particularly for students taking ESP (English for specific purposes) whose ability to communicate is minimal, and their oral expression poor. This is what I have encountered during my years of teaching in Iranian universities which is supported by the work of Iranian university teachers mentioned above. These problems are related to many factors such as lack of teacher training, cultural backgrounds, specific social context and the lack of English language as second language in Iranian society.

Since university students are to be specialized in a particular field should be enabled to use ESP. Brumfit (1981) noted that: First, it is clear that an ESP course is directly concerned with the purposes for which learners need English, purposes which are usually expressed in functional terms. ESP thus fits firmly within the general movement towards "communicative" teaching of the last decade or so. Similar definition of ESP has given by Strevens (1980) devised to meet the learners' particular needs; (2) related in themes and topics to designated occupations or areas of study (3) selective (i.e. not general) as to language content (4) when indicated, restricted as to the language skills included. But the distinctive differences between ELT and ESP are identified by many writers such as Widdowson (1978), Mackay and Mountford (1978), Crofts (1981) for 'occupational and professional' study.

Regarding settings as one of the other problems in the Iranian universities, the experiences in western teaching settings have proved that as you change the pattern of the seats to a circle, you will find more learning-taking place because people seem much more involved when addressing faces rather than the backs of heads in dense rows. Brown and Yule (1983) quoted Hymes (1972) that: A context can support a range of meanings. When a form is used in a context it eliminates the meaning's possible to that context other than those the form can be signed: the context eliminates from consideration the meaning possible to the form other that those the context can support.

Consequently, my main aim in this paper is to propose a new approach, suitable for the needs of an English language programme for Iranian English teachers and learners. Such an approach might provide a solution to this critical problem of lacking effective communication. This is critical, because apparently the main purpose of learning any language is to interact with others in that particular language, to convey information and exchange views. One important deficiency is the limited use of oral discourse analysis in the majority of English language classes.. Iranian university English learners, even after graduation, have urgent problems in the use of English language. Even though the majority of these learners know grammar and vocabulary at an advanced level, they are unable to use this knowledge orally. I found these points through my teaching experience and research. The main reason I found for this during my own teaching experience is that there are no oral practice opportunities or activities in designed course books, nor is this provided by the teachers in their teaching approaches. In fact, teaching/learning is not focused on oral performance and use of the English language. English language teachers apply their own methods to teach the students, which may incorporate a variety of teaching methods from the Grammar-Translation to the Audio-Lingual, but none are Communicative. The main purpose is to familiarise the learners with translation and reading the literature, and experiencing their native language through the grammar of the target language. Both the teacher and students focus on reading the target language and translating it into the native or L1 (mother language of the learners), using this language for most of the class time. For example, an English passage is read and translated into Farsi Language (L1) by the students. The teacher normally asks the questions and answers in Persian most of the time. This method puts more emphasis on reading and writing. Therefore, the students do not usually carry out oral performance in the target language and consequently it does not prepare the students for the use of the target language (English). Or normally the main purpose has been to use the target language in class activities with certain rules and structures. Although it is claimed that all four language skills are taught through this method, oral performance is very limited and it is insufficient for routine language use. In most cases certain aspects of language are emphasised and less attention is paid to communication. For example. in some classes a sort of rote learning through memorisation rather than internalisation and use of English is stressed. Imitating a language without understanding it may not be useful and the learners would not be able to make new speech patterns, in other words, it is a type of parrot learning. Structured learning is limited and does not help the learners to be empowered to initiate new patterns. This method provides insufficient practice to prepare learners for language expansion and use.

Therefore, these teachers obviously have difficulties in using English all the time in class, and those who have been educated in foreign countries are the sole speaker most of the time. We have seen that in the process of 
teaching/learning the teacher has not been giving learners opportunities to practise what they have been involved in, but rather has actually been preventing talk. The teacher's role, then, has been simply to interfere in the learning process.

English language learners in Iran are restricted in their language use generally by their textbooks, technological aids and even more so by the language teaching approaches employed by the teachers. In my experience, it is noticeable that in Iranian universities, the majority of the university students find it almost impossible to make themselves easily understood in a face-to-face discussion in English. This is chiefly due to the fact these students have been taught without using what they have learned, which has been grammar rather than content. Thus the teachers have been teaching the form of the language, rather than encouraging its use. In this case it is better to leave the English teaching to subject specialists as McDonough (1984) argued that: Learners being taught by a scientist with some language training will definitely have greater 'face validity' than lessons with a language teach unwilling or unable to engage in scientific procedure.

Still there is another problem of not many opportunities to use English in public. Riley (1982) argued that the teacher has to provide optimum conditions for learning via modelling as Wilson (1986) also noted that not only teachers should have a sound knowledge of English but also should know how to use the tools. Wright and Bolitho (1993) proposed that to help trainee participants to ask questions about language to enable them to be effective teachers. To summarise, I have cited Schiffrin (1994) to clarify the previous discussion: Given the vastness and variety of topics and issues that fall under the label it should not be surprising that a wide range of data can be used to illustrate how to go about doing on analysis of discourse.

\section{SOLUTIONS}

Teachers arguably need to be trained in order to know the context, subject matter and other necessary information such as the management features related to the class they are going to teach. Once teachers possess all this information they can cope better with their prospective problems, because they know the reasons and can find suitable solutions to prevent those issues. The application of oral discourse analysis as an effective method can help ELT in Iranian universities especially for students' speaking skills. In practice, this means that the students should be provided with as many opportunities as possible during their course. These will include everything from giving a short talk and answering questions on it to taking part in a group discussion in response to an extract from their materials covered in class or any new subject. This means students will be looking at their ability to vary their use of spoken language according to the needs and demands of the participants - their teachers and peers. Students and teachers need to know that, they need to:

a. Speak clearly, taking care that everyone can hear;

b. Show enthusiasm, show that the topic is interesting;

c. Be positive and friendly, with a sense of humour, and be approachable; eye contact is important;

d. Pause after an important point in order that the point may be understood by the other students and that they can be prepared to respond to any questions.

In addition the presenter should try to deliver the topic appropriately by the use of all available materials such as pictures, diagrams, gestures and any other educational aids.

Group work is one of the effective ways as in and out of the class practice in which when students are allowed to have discussion in small groups they will find opportunities to talk about their personal interest topics by the use of learned knowledge. This situation facilitates learning and new information is exchanged which will become deeply understood. Group work can improve the speaking skills of students. In group discussions are specific features which you can never find in individual talk. I used this strategy for research teaching sessions and found it significantly effective.

Settings is still another effective element for better language learning, for example, in circular kind of setting all learners become active participants. The teacher becomes a member of the circle. In this particular setting the most learning will take place. The class may experience some silence but that silence is constructive because participants have to think and prepare themselves as to how to fill the gap. This was what I have experienced occasionally in my previous years of teaching and this is why this type of classroom seating is in common use in Western countries. However, it is interesting to note that this circular type of setting is normal in most religious schools in Iran and these schools seem to have been more successful in their studies than schools using other kind of settings.

Recently the "Japan Association for College English Teachers" dealt with some issues in E.L.T. Butler and Lee (2006) pointed that according to Oba (1994), the aforementioned association decided to revise E.L.T. First, the text books needed some change, second the method of E.L.T be based on communicative method, not to be emphasized on conversation but a set of methods that reinforce communicative ability. This case for specialized fields must be focused on that particular field that, for instance in Law, specific terms related to law are concentrated. In spite of Japanese students and graduates who are reported so weak in almost all skills, Iranian's are not such in those skills, but are weak in listening and speaking skills. This needs to be practiced as much as possible in classes operated in academic atmosphere and more than that out of class, but to be assigned and checked by the instructors. This requires an Inservice teacher training particularly for the instructors with M.A. degree who have not been under any teacher-training. 
Newly issued studies on text and class materials showed that pretty interested assignments and individual task presentation materials are of the most students' needs met subjects.

\section{Conclusions}

English has been taught in Iranian universities according to the personal preferences of the teachers. Textbooks have been produced in a way that does not meet the real and practical needs of the university students, particularly for the use of English. These textbooks have been produced both before during the Cultural Revolution, but no particular approach has been introduced to English language teaching. Consequently, Iranian university English instructors have not been using up-to-date or currently approved methods of teaching. English teaching would arguably involve practical face-toface interaction in the classroom and the use of audio-visual aids for independent practice out of the classroom. English language students are really concerned about their difficulties in using English in their academic fields. This is a result of the type of approach used in English classes. The thoroughness of English learners' use of the language depends largely upon the vocabulary used in the topic under discussion and can expand by the use of synonyms.

Educational aids facilitates speed; as illustrations can be used to stimulate the students to talk. Students can follow the patterns presented by a tape recorder, videotape or a movie. These technological aids may provide English learners with authentic speech from a native English speaker, which they may not otherwise encounter.

\section{REFLECTION AND RECOMMENDATIONS}

In fact, despite the past long history of English teaching in Iran, the following may possibly influence its improvement:

a. Offer useful learning/teaching strategies.

b. Assess and provide suitable teaching materials that meet the needs of the students, as well as:

- Convince English language learners that the approach (learner-centred) works effectively and renders a maximum gain in learning such as offering them a clear opportunity for exercises in comprehension by means of listening activities, in order to utilise these as patterns for practice.

- Motivate students to learn by utilising benefits from the students' own experiences.

- Acknowledge how an open exchange views may enhance the insights of both teachers and students.

- Practise focused oral communication from the beginning in the belief that: "practice makes perfect".

The abilities, acquired as a means of expression, would enable English language students to use the English language more easily and more fluently without the need for the full mastery of grammatical structures.

1. Class initiatives: this strategy can be implemented in steps:

1) English teachers are aware of the ongoing activity in the class and make the students understand the purpose of the English classes.

2) Teachers in English classes use diverse means such as describing pictures, using students' shared knowledge to facilitate utterances.

3) Teachers/learners focus on functional communication for meaning.

4) Teachers provide students with a situation in which they will find themselves, in a confident and friendly environment; and also explain to the students the rationale of such classes.

5) Teachers assign the students to explore various ways and strategies to achieve a particular goal. They give them the opportunity of acting the roles assigned to them.

2. use of educational technology: One facilitator of good teaching is sound technology properly used. That is, the type of technology which provides the students with their real needs. Nowadays, educational technology plays a vital role in the promotion of the learning process; although these instruments are hardly available in our Iranian English classes. Nevertheless, it is recommended to use any available technology because sometimes they can be helpful in a unique way, for example, hearing an English native speaker's voice. These tools, cassettes, videos, computers and projectors, can be used both in class and/or out of class at home such as in the car or wherever possible. For example, video provides English learners with real communicative situations in which the learner can shift the role. Becoming an active participant, rather than a passive observer, promotes productive oral skills. It also helps the students to regain their emotional composure and motivation. Video is useful in enhancing vocabulary, structures, functions and paralinguistic features, that is, vocal effects which change the meaning and via discussion, register as I mentioned earlier.

3. use of effective and purposeful input: The main aim in oral discourse analysis for English classes is to enable students to speak fluently and purposefully. Speaking is a productive skill that presupposes a basic receptive skill readiness. Receptive skills such as listening and comprehending must be well practised for sense and specific information, to prepare for a sound productive skill. Therefore, the first element which influences these skills is effective input. This is together with the ability to listen because a good listener through production practice will become a good speaker. Thus, input must be clear in production and simple in structure with key vocabulary. This activates thinking about the topic and matching information. Listening faculties must be sensitive to perceive and internalise the input efficiently. Listeners are attentive and rehearse the main sounds and the key words. 
4. question and answer strategy: the question and answer strategy is a strong practice technique. This practice is performed by asking for volunteer students at the very beginning, and varies between simple questions to lengthy ones. Afterwards, students may be asked various questions by the teacher, peers or visitors. Materials in textbooks may be used in the form of questions for practise. In particular, when materials are provided in a way to meet the needs of the students, they help the students to focus on suitable chosen topics. This saves students' time searching for relevant topics.

5. level of simplification use: students with low competence, would use simplification strategy to use simplified terms at the beginning and gradually substitute them for the appropriate technical terms, because specific lexis/terms conventionally signify concepts to efficient utterances within a specific context. Hence, the simplification strategy facilitates oral presentation and the use of teaching materials. This strategy suits the text of both lexical and structural formation as well as the students' needs and situations, level of knowledge and conceptualised context. Simplification enhances the development of language use. It varies according to specific context, topics, facilities, time, environment, and discipline, teaching style, and expectation. This strategy moves from analysis to synthesis, by splitting a text into simple parts. The rationale for the use of simplification is that in English programme, the allotted time is not sufficient to perform all and every individual task of the material and related activities.

6. level of synonymous use: use of the synonym is one of the other strategies that would help the learners to fill the pauses which would be caused by unfamiliar words. This strategy also enables the learners to perform continuous utterances. Learners, through the use of synonyms, would make some usage patterns, such as using a series of connectives, affixes or propositions.

7. use of group work: generally, a discussion offers the students the opportunity to demonstrate their oral skills in situations where collaboration and co-operation with other students and peers is important. Students need to be prepared and list their points, if any, they want to discuss; sit in a semi-circle; try to use facts to follow up and support others' views. Group discussion will be most fruitful and will be maximised when discussion is with attention, motivation, and purpose. The key point is that English students do their best to make a concrete statement to express specialised propositions.

The class is learner-centred; that is, everything is arranged to maximise the use of English language by the students. Use of language is segmented into fragments as functional units. When students' language skill needs have been determined by the designer/s the appropriate teaching method must be employed to meet these needs Students should attempt to follow the discussion in longer phrases without interruption. Students speak at the first possible opportunity. This means they use English language even in an informal manner. This can be done by choosing and using familiar terms and expressions. Students use contextualised speech and appropriate linguistic resources. When a discourse gap occurs, students use expressions such as 'pardon me', 'say it again please' and the like to continue their discussion.

It is hoped that these recommendations will serve as effective facilitators and a guide for ELT in Iranian universities and a stimulus to ELT teaching and research. That is why selected instructors from Iranian universities despite all the difficulties are sent abroad to search, identify and propose the workable effective research methods, teaching strategies and many more aspects of advanced work in different disciplines taken from other countries through their theoretical and research works. However, this is not the end of the story and certainly we do need more study and more research if we are to overcome all the problems which never ends.

\section{REFERENCES}

[1] Bates, M. (1978). Writing Nucleus, in R. Mackay and A. Mountford (Eds.), English for Specific Purposes, 7(1), $32-53$.

[2] Biria, R. \& Tahririan, M. H. (1994). The Methodology Factor in Teaching ESP, English for Specific Purposes, 13(1), 93-101.

[3] Brown, G. \& Yule, G. (1983). Discourse Analysis, Cambridge University Press, Oxford, U.K.

[4] Brumfit, C. J. (1981). National Syllabuses Revisited: A Response, Applied Linguistics, 2(1), 34-42.

[5] Butler, Y.G. \& Lee, J. (2006). On-task versus off-task self-assessments among Korean elementary school students studying English, Modern Language Journal, 90(4), 54-67.

[6] Crofts, J. N. (1981). Subjects and Objects in Teaching Materials, in Selinker, Tarone and Hanzeli (Eds.), English for Academic and Technical Purposes, 11(1), Newbury House Pub., 281-290.

[7] Flowerdew, S. (1994). frameworks and Contexts: A Genre-based Approach to Analysing Lecture Introductions, English for Specific Purposes, 13(2), 171-186.

[8] Hymes, D. (1972). Directions in Sociolinguistics, Holt, Rinehart and Winston Pub., New York.

[9] Jamshidi Avanaki, H. (1998). University Teacher-Training in Change: The English and Iranian Experience, English Language Teaching in the Two Systems with ESL/ESP as a Case Study. PhD Thesis, Sheffield University, Sheffield University Press.

[10] Larsen-Freeman, D. \& Long, M. H. (1991). An Introduction to Second Language Acquisition Research, Longman Group Ltd., U.K.

[11] Mackay, R. \& Mountford, A. (1978). English for Specific Purposes, Longman Pub., London.

[12] McDonough, J. (1984). ESP in Perspective: A Practical Guide, Collins Educational Pub., London.

[13] Oba, J., (1994), Where have the liberal Arts gone?, in Ohsaka T. Et al (Eds) The Conduct of the University. Tokyo: RodoJunposha.

[14] Riley, P. (1982). Topics in Communicative Methodolgy: Including a Preliminary and Selective Bibliography on the Communicative Approach, Longman Pub., London.

[15] Sayer, P. (2005). An intensive approach to building conversation skills, ELT Journal, 59(1), Oxford University Press, 14-22. 
[16] Schiffrin, D. (1994). Approaches to Discourse, Blackwell Pub. Oxford, U.K.

[17] Shinji Kondo, D. \& Ying-Ling, Y. (2004). Strategies for coping with language anxiety: the case of students of English in Japan, ELT Journal, 58(3), Oxford University Press, 258-265.

[18] Smith, R.C. (2006). Teaching English as a Foreign Language 1912-1936: Pioneers of ELT, ELT Journal, 60(1), Oxford University Press, 79-83.

[19] Strevens, P. (1980). Teaching English as an International Language, Pergamon Pub., Oxford, U.K.

[20] Widdowson, H. G. (1978). Teaching Language as Communication, Oxford University Press, Oxford, U.K.

[21] Wilson, J. (1986). ESP for the University, Pergamon Press, Oxford, U.K.

[22] Wright, T. \& Bolitho, R. (1993). Language Awareness: A Missing Link in Language Teacher Education, English Language Teaching, 47(4), 292-302.

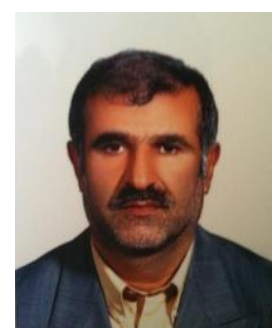

Hossein Jamshidi Avanaki, was born in Qazvin, Iran on 2/5/1948. He graduated from Tehran University, Iran, with a B.A. in English language and literature, obtained a M.A. in Teaching from Shahid Beheshti University, Iran, and a M.Ed. from Ottawa University, Ottawa, Canada in 1993. He obtained his Ph.D. degree in English Teaching from Sheffield University, Sheffield, U.K., with thesis entitled "University TeacherTraining in Change: The English and Iranian Experience, English language Teaching in the two systems with ESL/ESP as a Case Study" in 1998.

He, as a University Lecturer, has been lecturing at various Iranian universities since 1979, teaching general English and E.S.P. courses to university students in different departments. Moreover he has been involved in translating and editing UNESCO magazines as translator and editor during years 1981 to 1984 . At the present, he is an English Lecturer at Payame-Noor University, Qazvin city branch, Iran.

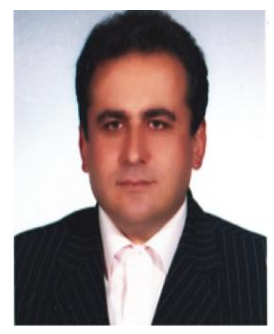

Bahador Sadeghi, an assistant professor of Applied Linguistics holds a doctorate degree in TEFL from the University of Isfahan, Iran. He also holds three MAs in Applied Linguistics (TEFL), Translation Studies and International Relations from Tehran Islamic Azad University, Isfahan University and Allameh Tabatabai University respectively. He has been lecturing different subjects in Teaching English, Translation studies, Discourse Analysis, ESP and other related topics at several universities in Iran for the last twenty three years. $\mathrm{He}$ has both published and presented a number of articles in some international journals and conferences. $\mathrm{He}$ is also a certified translator to the judiciary power in Iran and he has been, as a simultaneous interpreter, actively involved in many national and international seminars, sport events and tourism projects. 